\title{
The Culture of the Rumen Organism Eadie's Oval in vitro
}

\author{
By C. G. ORPIN \\ Department of Biochemistry, Agricultural Research Council, \\ Institute of Animal Physiology, Babraham, Cambridge
}

(Accepted for publication I 3 November I97I)

\begin{abstract}
SUMMAR Y
Clone cultures of two strains of the rumen organism Eadie's Oval were established in vitro. Both strains were maintained anaerobically at 38 to $40^{\circ}$ in liquid culture in the presence of bacteria, rumen fluid, a reducing agent and a $\mathrm{CO}_{2}$ gas phase. There was no growth in sterile or solid media. Growth and storage of glycogen occurred when each strain was incubated with one of a small range of simple carbohydrates; amino acids, fatty acids, proteins and polysaccharides did not support growth or glycogen synthesis. Neither strain survived freezing, but cultures were viable after two weeks at $4^{\circ}$; incubation at $44^{\circ}$ resulted in no growth or the death of cultures.
\end{abstract}

\section{INTRODUCTION}

Eadie (I962) observed that a large oval organism appeared occasionally in the developing rumen of isolated lambs. She described these organisms as motile, up to $12 \mu \mathrm{m}$ in length, without visible locomotory organelles, and showing some internal structure when examined by ultraviolet microscopy. Later workers have referred to this organism as 'Eadie's Oval'; no taxonomic name has been assigned to it and very little has appeared in the literature concerning this species. Eadie's Oval (E.O.) has been observed in $90 \%$ of the sheep so far examined by the author, and has been reported by Abou Akkada \& El-Shazly (1964) from Egypt and by Warner (I966) from Australia. Quin (1943) stated that oval organisms, larger than the 'Quin's Ovals' (Q.O.) described in the same paper, occurred in the rumen of cattle in South Africa, but did not describe them further; these may have been E.O. In the rumen contents examined by the author, the population of E.O., when present, varied from $4.5 \times 10^{5}$ to $\mathrm{I} \cdot \mathrm{I} \times 1 \mathrm{IO}^{8} / \mathrm{ml}$. It appears that this organism is a normal member of the rumen microbial population of sheep, but one which does not occur in all animals. It was apparently overlooked by earlier workers.

A preliminary communication (Orpin \& Coleman, 1970) described the culture of a strain of ovals in vitro, but due to lack of information on the morphology and characteristics of E.O. and Q.O. in the literature, it was not possible to identify the cultured organism at that time. Dr J. M. Eadie has since kindly identified it as being E.O. Clone cultures of this organism and of a second strain of the same species isolated from the rumen of a different sheep are the subject of this paper. As far as the author is aware E.O. has not been grown in vitro before: strain I has been cultured in vitro for I 5 months, and strain 2 eight months.

\section{METHODS}

Culture media. The standard culture medium consisted of a solution in $10 \%(\mathrm{v} / \mathrm{v})$ autoclaved rumen fluid (ARF), containing (g/l): $\mathrm{KH}_{2} \mathrm{PO}_{4}, 4.9 ; \mathrm{KH}_{2} \mathrm{PO}_{4}, 2 \cdot 8 ; \mathrm{NaCl}$, I.27; $\mathrm{CaCl}_{2}$ (dried), $0.035 ; \mathrm{MgSO}_{4} \cdot 7 \mathrm{H}_{2} \mathrm{O}, 0.07$ and $\mathrm{NaHCO}_{3}, 6.5 ;$ L-cysteine hydrochloride 
(neutralized immediately before use), $0 \cdot 2 ;$ glucose, $0 \cdot 2$. The medium was equilibrated with $\mathrm{CO}_{2}$ and dispensed, with $\mathrm{CO}_{2}$ flowing through all the containers, into $6 \times \frac{5}{8}$ in or $8 \times \mathrm{I}$ in test tubes in $10 \mathrm{ml}$ or $50 \mathrm{ml}$ volumes respectively. Each tube was then bubbled vigorously with $\mathrm{CO}_{2}$ for at least $\mathrm{I}$ min and the tube sealed with a rubber bung as the gassing pipette was withdrawn.

Sterile media were prepared by the separate sterilization of the inorganic salts (excluding the sodium bicarbonate), by autoclaving at $110^{\circ}$ for $20 \mathrm{~min}$; L-cysteine, glucose and sodium bicarbonate were separately Seitz-filtered. The constituents were combined aseptically in each culture tube, and equilibrated with $\mathrm{CO}_{2}$ by bubbling with $\mathrm{CO}_{2}$ for not less than 3 min before sealing with a rubber bung.

Solid media were prepared by autoclaving I \% agar (Davis) and $0.000 \mathrm{I} \%$ resazurin with the medium, which was then kept at $45^{\circ}$ in a water bath while the resazurin was decolorized by bubbling with $\mathrm{CO}_{2}$. Inoculation was performed with $\mathrm{CO}_{2}$ flowing freely over the medium. Unless otherwise stated, all inoculated media were incubated at $39^{\circ}$.

Rumen fluid fractions. Rumen fluid from Clun Forest wethers, fed daily on $800 \mathrm{~g}$ of hay chaff and $200 \mathrm{~g}$ of crushed oats, was strained through one layer of muslin to remove coarse particles. The filtrate was autoclaved $\left(\mathrm{I} 5^{\circ}, 20 \mathrm{~min}\right.$ ) under $\mathrm{CO}_{2}$, to produce 'crude autoclaved rumen fluid' (CARF). Strained rumen fluid was centrifuged at Iooog for 5 min to sediment the protozoa, larger bacteria and larger plant material; the supernatant was autoclaved under $\mathrm{CO}_{2}$ to produce 'autoclaved rumen fluid' (ARF). The same supernatant fraction was also centrifuged further at $2500 \mathrm{~g}$ for $30 \mathrm{~min}$ to yield 'particulate fraction $\mathrm{A}$ '. The supernatant from this was then centrifuged successively at $7500 \mathrm{~g}$ for $30 \mathrm{~min}$ to yield 'particulate fraction $\mathrm{B}$ ', and at $\mathrm{I} 2,500 \mathrm{~g}$ for $30 \mathrm{~min}$ to yield 'particulate fraction $\mathrm{C}$ '. Each fraction was washed by centrifugation in the salts solution used in the media, and resuspended in this solution to the original volume and autoclaved (I I $\left.5^{\circ}, 20 \mathrm{~min}\right)$. The supernatant was also autoclaved, producing 'autoclaved supernatant' (AS). Fresh rumen fluid was centrifuged at $15,000 \mathrm{~g}$ for $60 \mathrm{~min}$ to yield a clear supernatant, designated 'fresh centrifuged rumen fluid' (FCRF).

Counting and measurement. Organisms were counted using a conventional haemocytometer chamber with Thoma ruling, depth $0.1 \mathrm{~mm}$. All the refractile E.O. on the grid were counted. When less than 20 cells were present, four samples were counted and an average calculated. Dimensions were measured using a calibrated micrometer eyepiece.

Isolation of strains. Strain I was isolated from the cultures described by Orpin \& Coleman (I970), by the micromanipulation of a single organism. At this stage no precautions were taken to eliminate contaminating bacteria. This organism was inoculated into $\mathrm{I} \cdot 0 \mathrm{ml}$ of medium, and incubated under $\mathrm{CO}_{2}$. The supernatant fluid was sucked off and replaced with fresh medium daily for two weeks, after which time a number of organisms were visible in direct microscopic examination of the culture tubes. Only one clone was established from 54 individual organisms, all of which were incubated and treated identically. The volume of culture fluid was then increased to $2.0 \mathrm{ml}$, and $0 . \mathrm{I} \mathrm{ml}$ of $0.4 \%(\mathrm{v} / \mathrm{v})$ glucose added daily; the supernatant fluid was sucked off and replaced by fresh medium every three days. After a further two weeks, the culture volume was increased to Io $\mathrm{ml}$ and $0 . \mathrm{I} \mathrm{ml}$ of $2 \%(\mathrm{w} / \mathrm{v})$ glucose solution was added daily. Thereafter the culture was divided at weekly intervals into two portions of equal volume, and the volume of each made up to the original volume with fresh medium. $\mathrm{CO}_{2}$ was allowed to flow through the container at all times during the division. The population density prior to the commencement of the weekly division routine was $\mathrm{I} \cdot 2 \times 10^{6} / \mathrm{ml}$.

Strain 2 was isolated by a less lengthy procedure. Rumen fluid from another Clun Forest wether, containing a population of $5 \times 10^{6} \mathrm{E} . \mathrm{O} . / \mathrm{ml}$, was filtered through one layer of muslin 
to remove coarse particles and allowed to stand for $\mathrm{I} h$ at $39^{\circ}$ to let the larger material, including the ciliate protozoa, sediment. The supernatant ( $10 \mathrm{ml}$ ) was centrifuged at $1000 \mathrm{~g}$ for I $5 \mathrm{~min}$, the supernatant from this was decanted and the precipitate, containing the E.O., resuspended in Io $\mathrm{ml}$ of standard culture medium. The suspension was centrifuged in $\mathrm{CO}_{2}$-gassed, stoppered centrifuge tubes at $500 \mathrm{~g}$ for $20 \mathrm{~min}$ and the sedimented ovals resuspended in $12 \mathrm{ml}$ of medium. This suspension $(0.05 \mathrm{ml})$ was added to $10 \mathrm{ml}$ of medium contained in 6 in $\times \frac{5}{8}$ in test tubes, gassed with $\mathrm{CO}_{2}$, stoppered tightly and incubated. The next day the supernatant was replaced with fresh medium, after which $0 \cdot \mathrm{I} \mathrm{ml} \mathrm{of} 2 \%(\mathrm{w} / \mathrm{v})$ glucose was added daily. After one week, the population of E.O. had increased from $6 \times 10^{4} / \mathrm{ml}$ to $3 \times 10^{6} / \mathrm{ml}$. Single organisms were then picked out by micromanipulation and incubated separately in I $\mathrm{ml}$ of medium. These tubes were then treated in the same manner as strain I. After two weeks, clone cultures had arisen from eight of the picked organisms; only one clone, strain 2, grew vigorously. The volume of the culture containing strain 2 was increased to $\mathrm{IO} \mathrm{ml}$, and the population density allowed to rise to $25 \times 10^{6} / \mathrm{ml}$ prior to the weekly division of the culture.

Cultures of $50 \mathrm{ml}$ of both strains were established by adding $10 \mathrm{ml}$ of fresh medium twice a week for two weeks to Io $\mathrm{ml}$ cultures growing in 8 in $\times \mathrm{I}$ in test tubes.

No individually selected organisms of either strain grew when incubated in the original medium in the absence of bacteria; 76 organisms of strain 1 and 52 organisms of strain 2 were incubated in this manner.

Maintenance of cultures. Cultures were fed daily with $0.2 \mathrm{~g} / \mathrm{l}$ of glucose, with the exception of the day following the weekly division of the culture into two; this division was performed by diluting a culture with an equal volume of fresh medium, half being dispensed into a new culture tube. To ensure the maintenance of a good growth rate it was necessary to examine the contents of each tube at least once a week using an inverted microscope, then, if growth was not good or the growth of contaminating bacteria excessive, the supernatant fluid was replaced with fresh medium. This usually restored growth to its normal rate; if not, the culture was discarded.

The preparation of inocula used in growth experiments. The organisms used in experiments involving media which varied from the standard only in the possession of a different carbon source were prepared from $\mathrm{I}$ o $\mathrm{ml}$ cultures grown in standard medium. In the cultures, the E.O. formed a loose pellet in the bottom of the tube so the supernatant fluid was sucked off, the remaining material gassed with $\mathrm{CO}_{2}$, and the E.O. resuspended in $10 \mathrm{ml}$ of standard medium from which the glucose was omitted (suspension A). Suspension A was centrifuged at $800 \mathrm{~g}$ for $5 \mathrm{~min}$ and the sedimented E.O. washed twice by the same method in the same medium. The final sediment was resuspended in Io $\mathrm{ml}$ of fresh glucose-free medium and $\mathrm{I} \mathrm{ml}$ of this suspension used to inoculate tubes containing $9 \mathrm{ml}$ of the experimental medium. Inocula used in experiments with different reducing agents were prepared similarly, except that $\mathrm{I} \mathrm{ml}$ quantities of suspension A were added to $9 \mathrm{ml}$ of the new medium. Traces of the old medium were removed by two washings by centrifugation, and the organisms resuspended in the new medium. When inocula for experiments containing different rumen fluid fractions were prepared, suspension A was prepared in rumen fluid-free medium, and subsequent washings performed in the same medium. Similarly, for experiments with different gas phases, I ml portions of suspension A were washed in medium equilibrated with the new gas phase (sodium bicarbonate was omitted from the medium when $5 \% \mathrm{CO}_{2}+95 \% \mathrm{~N}_{2}, \mathrm{~N}_{2}$ or air were used). All centrifugations were performed under the appropriate gas phase in stoppered tubes.

Preparation of suspensions of ovals essentially free of other bacteria. The supernatant 
liquid of growing cultures was sucked off, leaving the E.O. in the material in the bottom of the tubes, and the combined suspensions made up to $100 \mathrm{ml}$ in a measuring cylinder with salts containing $0.02 \%(\mathrm{w} / \mathrm{v})$ of L-cysteine hydrochloride and equilibrated with $\mathrm{CO}_{2}$. The whole was then gassed vigorously with $\mathrm{CO}_{2}$ for $5 \mathrm{~min}$, stoppered, and allowed to stand for 20 min while the larger particulate material sedimented. The supernatant was siphoned off and stored under $\mathrm{CO}_{2}$. The precipitate was resuspended in the same medium and resedimented under the same conditions. The combined supernatants were centrifuged at $100 \mathrm{~g}$ for Io min to remove more coarse material, and then at $500 \mathrm{~g}$ for $15 \mathrm{~min}$ at $5^{\circ}$ under $\mathrm{CO}_{2}$. The precipitate of ovals was repeatedly centrifuged under the same conditions until the supernatant was clear. The number of centrifugations varied with each batch of cultures, as both the contaminating bacterial population and the particle size distribution in the rumen fluid used varied between batches. Average preparations of E.O. obtained contained I other bacterium to I 50 E.O., as determined by phase-contrast microscopy.

Estimation of glycogen. Samples $(\mathrm{I} \cdot 0 \mathrm{ml})$ of the suspensions were centrifuged at $800 \mathrm{~g}$ for I $5 \mathrm{~min}$ and the pellet resuspended in I $\mathrm{ml}$ of $20 \%(\mathrm{w} / \mathrm{v}) \mathrm{KOH}$. The suspension was heated on a boiling water bath for $20 \mathrm{~min}$ and centrifuged at $2600 \mathrm{~g}$ for $15 \mathrm{~min}$. The supernatant was then treated with $2.5 \mathrm{vol}$ of absolute ethanol, and the precipitated glycogen sedimented be centrifugation at $2600 \mathrm{~g}$ for $30 \mathrm{~min}$. The glycogen was washed by centrifugation in ethanol, and the excess ethanol removed by passing a stream of air over the pellet until it was dry. The glycogen was hydrolysed with $\mathrm{I} \cdot 0 \mathrm{ml}$ of $2 \mathrm{M}-\mathrm{HCl}$ on a boiling water bath for $20 \mathrm{~min}$; the hydrolysate was diluted to $10 \mathrm{ml}$ with water, and the glucose liberated estimated by the method of Park \& Johnson (I949).

\section{RESULTS}

\section{Morphology}

Size of organism. E.O. cultured in vitro varied in size ( 8 to $20 \times 6$ to I $2 \mu \mathrm{m}$ ), depending upon the cultural conditions. Typical E.O. were depicted by Eadie (1962). Strain I tended to be larger than the E.O. usually present in the rumen, averaging $10.2 \times 7 \cdot 1 \mu \mathrm{m}$, when initially isolated. When the weekly division routine had been established this strain exhibited a cyclic variation in the length of the organism with the age of the culture after the day of division. Typically, two days after cultures were divided the average length of E.O. was II $\cdot 2 \mu \mathrm{m}$. After five days this had increased to $15 \cdot 2 \mu \mathrm{m}$ and after eight days (the day of the next successive division) to $16 \cdot 8 \mu \mathrm{m}$. Two days after the next division the length had reverted to about II $\cdot 2 \mu \mathrm{m}$, and the cycle repeated itself. The width remained constant at approximately $8 \mu \mathrm{m}$. If the cultures were allowed to remain undivided, the size of the organisms usually increased to 50 to $200 \times$ I 2 to $20 \mu \mathrm{m}$ within 3 to 4 weeks, with a few organisms in excess of $250 \times 30 \mu \mathrm{m}$. These enormously enlarged organisms were frequently extremely distorted; possibly a component of the medium produced by bacterial metabolism prevented normal division. After culture for a further 6 months this cyclic variation had ceased, but individual organisms of up to $100 \mu \mathrm{m}$ long and chains of up to 12 otherwise apparently normal organisms occurred in some cultures.

Strain 2 averaged $\mathrm{II} \cdot \mathrm{I} \times 7 \cdot 0 \mu \mathrm{m}$ after isolation. Cultures did not show the cyclic size variation shown by strain $I$, although their size was irregularly variable. The maximum size observed during routine culture was $20.4 \times 9.6 \mu \mathrm{m}$.

Comparison with Quin's Oval. E.O. was larger than the organisms resembling the Q.O. described by Quin (1943) as occurring in the sheep rumen, the individual organisms having a lower length to breadth ratio. In the sheep at the author's laboratory, E.O. averaged 
I $2 \cdot 2 \times 8 \cdot 5 \mu \mathrm{m}$ and Q.O., $7 \cdot \mathrm{I} \times 3 \cdot \mathrm{I} \mu \mathrm{m}$; their respective length to breadth ratios being $\mathrm{I} \cdot 44$ and $2 \cdot 19$.

Both species are iodophilic, staining deep brown. The iodophily of E.O. grown in vitro varied considerably with the state of nutrition of the organism: organisms not fed for $48 \mathrm{~h}$ stained very lightly, with an irregular distribution of stain.

The movement of the two species is different: E.O. have a direct gliding movement, frequently traversing large distances (many organism lengths) in a straight line, slowly rotating about the longitudinal axis; Q.O. have a rather erratic, jerky movement, rarely travelling more than three to four lengths in a straight line.

Light microscopy of whole cells. Phase-contrast microscopy of actively growing cultures of both strains of E.O. showed the organisms to be very refractile, with no cellular constituents being clearly visible. The refractivity decreased with time and granular inclusions became visible when the cultures were not given glucose daily. Most of these inclusions had disappeared within $48 \mathrm{~h}$ of the addition of glucose and the cells eventually became transparent, with the few remaining granules clustered near the centre. These granules and those present in unstarved organisms, stained readily with Best's Carmine, indicating that they consisted of glycogen-like material. Both strains were Gram-negative, and in both cases the distribution of stain was uneven, giving the organisms a mottled appearance, suggesting an uneven outer envelope. This phenomenon has also been observed by J. M. Eadie (personal communication). Starved organisms stained with Feulgen stain did not show the presence of discrete nuclear material. Both strains reproduced by binary fission, the daughter organisms normally being of equal size. No locomotory organelles were visible.

\section{Cultural conditions}

The effect of temperature. The growth rates of the organism at $25^{\circ}, 39^{\circ}, 44^{\circ}$ and $50^{\circ}$ were determined by incubating fresh cultures at these temperatures, glucose $(0.02 \%, \mathrm{w} / \mathrm{v})$ being added daily. Both strains grew optimally at $39^{\circ}$. At $44^{\circ}$, strain I organisms increased in size and became spherical and the population density remained constant, whereas strain 2 died within two days. At $50^{\circ}$ both strains died rapidly. At $25^{\circ}$, the population density of both strains remained constant for two days, after which the numbers of organisms decreased. The effect of low temperature was studied by placing the organisms, suspended in fresh standard medium, at $-20^{\circ}$, with or without glycerol, or at $4^{\circ}$. At the end of the experiment suspensions were removed, and those that were frozen allowed to thaw; the supernatants of all suspensions were replaced with fresh standard medium, and the cultures incubated at $39^{\circ}$. Glucose $(0.02 \%, \mathrm{w} / \mathrm{v})$ was added at daily intervals. In all cases, the population was determined daily. Both strains survived two weeks at $4^{\circ}$, though after one day of incubation at $39^{\circ}$, the population had reduced by $10 \%$. The initial population density was, however, regained after three days of incubation at $39^{\circ}$. Neither strain survived freezing at $-20^{\circ}$ for $\mathrm{I} h$, even if glycerol (up to $20 \%, \mathrm{v} / \mathrm{v}$ ) was added prior to the experiment.

The effect of reducing agents. Strain I incubated in the standard culture medium without L-cysteine failed to grow, and the population density fell from $4.6 \times 10^{4} / \mathrm{ml}$ to zero within five days. The numbers per $\mathrm{ml}$ after incubation for 5 days in L-cysteine-free standard medium supplemented with various reducing agents at $0.0 \mathrm{I}$ and $0.02 \%$, expressed as a percentage of the original inoculum, were respectively: L-cysteine, I74 and 248; sodium dithionite, 235 and 152 ; sodium thioglycollate, 183 and 260; ascorbate, 24I and 132 ; sodium sulphide, 135 and 102; and 2-mercaptoethanol, 152 and 239. Similar results were obtained with strain 2 , except that with $0.02 \%$ sodium sulphide the numbers were higher at 222. 


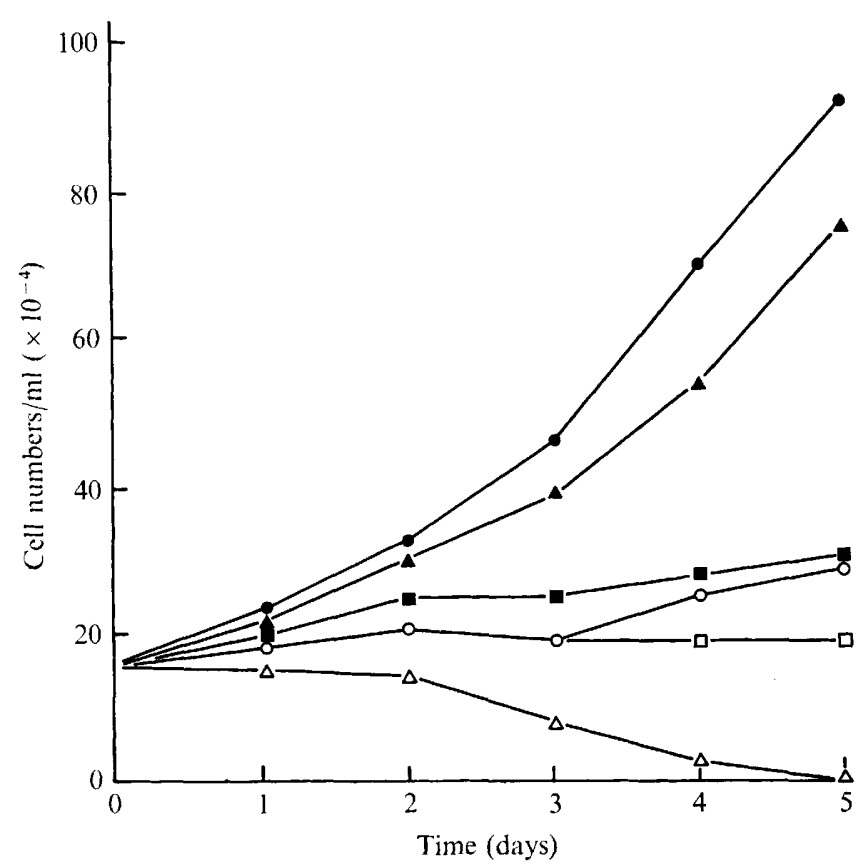

Fig. I. Growth of Eadie's Oval in the presence of different rumen fluid fractions. Each tube contained ARF-free standard medium (9.0 $\mathrm{ml})$ supplemented with ARF or factions prepared from $\mathrm{I} \cdot 0 \mathrm{ml}$ of strained rumen fluid, and $\mathrm{I} \cdot 0 \mathrm{ml}$ of a suspension of E.O. to give initially $16 \times 10^{4}$ organisms $/$ $\mathrm{ml}$ in the final volume. Glucose $(0.02 \%, \mathrm{w} / \mathrm{v})$ was added to each culture daily, and cells were counted after incubation for five days. The fractions added were: $O$, ARF or CARF; $\Delta$, FCRF or C + AS; D, AS or B + AS or A+AS; $O, \mathrm{~B} ; \square, \mathrm{A}$ or $\mathrm{C} ; \triangle$, none. For preparation of fractions see text.

The effect of different gas phases. No growth occurred when E.O. were incubated aerobically, or anaerobically under $\mathrm{N}_{2}$ or $5 \% \mathrm{CO}_{2}+95 \% \mathrm{~N}_{2}$. In all cases numbers dropped from $4 \times \mathrm{IO}^{5} / \mathrm{ml}$ to zero within five days. With $100 \% \mathrm{CO}_{2}$, numbers increased to $\mathrm{I} 2 \times \mathrm{IO}^{5} / \mathrm{ml}$ with strain I and $46 \times 10^{5} / \mathrm{ml}$ with strain 2 .

The effect of rumen fluid. There was no growth in the standard medium without ARF, in the medium without rumen fluid of Caldwell \& Bryant (1966), reinforced clostridial medium or thioglycollate medium. If the ARF was replaced in the standard medium by the fractions A, B, C or AS separately, only a limited growth occurred (Fig. I). If, however, C was combined with AS, growth approached that attained in media containing ARF. Fraction A or B combined with AS did not increase the growth rate over that of AS.

Growth in solid media. No growth was observed up to one month after the inoculation of the solidified standard culture medium, or medium of Caldwell \& Bryant (1966), with either strain taken directly from culture tubes.

Growth in the presence of carbohydrates. The growth of E.O. in the presence of carbohydrates other than glucose was determined by substituting the other carbohydrates at a concentration of $0.02 \%$ for glucose in the standard medium, and inoculating with $10 \%$ $(\mathrm{v} / \mathrm{v})$ of a suspension of glucose-grown organisms.

Both strains grew on glucose or fructose; strain I also grew on galactose and strain 2 on mannose. Both strains grew on sucrose or lactose; strain 2 also grew on cellobiose. There was no growth on arabinose, xylose, rhamnose, sorbose, lactose, cellobiose, maltose, trehalose, raffinose, cellulose, starch or inulin, and the alcohols ribitol, sorbitol and galactitol. 


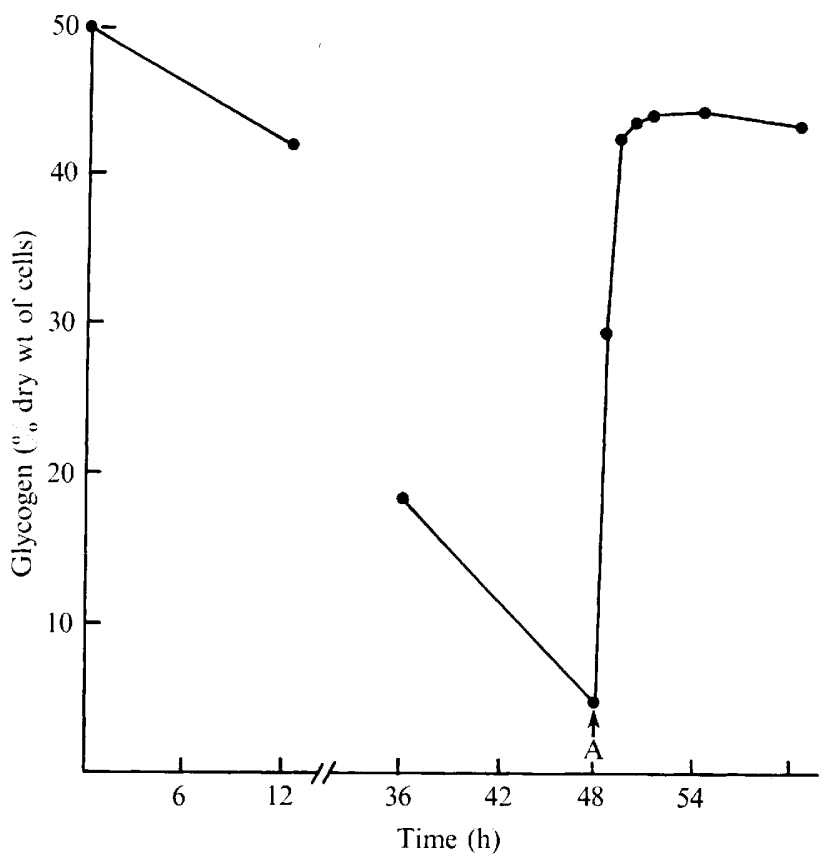

Fig. 2. Storage of glycogen by Eadie's Oval Strain I. E.O. (50 mg dry wt) essentially freed of other bacteria, were suspended in $15 \mathrm{ml}$ of glucose- and ARF-free standard medium. Samples ( $1 \cdot 0 \mathrm{ml}$ ) were removed periodically, centrifuged repeatedly at $800 \mathrm{~g}$ for $5 \mathrm{~min}$ until the supernatant was clear and free of bacteria, and the E.O. assayed for glycogen content. At point A, $0.05 \mathrm{~g}$ of glucose was added.

When E.O. strain I cultures were starved for $48 \mathrm{~h}$ in order to deplete the organisms of glycogen, essentially freed of bacteria by differential centrifugation and incubated with glucose (Fig. 2), fructose, sucrose or lactose, glycogen synthesis commenced immediately.

Neither strain was able to grow or store glycogen when incubated in glucose-free standard medium supplemented with $0.04 \%(\mathrm{w} / \mathrm{v})$ of compounds which could be generated by the bacterial fermentation of carbohydrates, acetate, propionate, butyrate, lactate or succinate. This indicated that the organisms were utilizing and converting to glycogen the carbohydrates themselves, and not the fermentation products produced from those carbohydrates by the other bacteria in the culture medium.

Strain 2, but not strain I, grew in the presence of salicin and aesculin, although the rate of growth was $30 \%$ less than that with glucose. Organisms starved for $48 \mathrm{~h}$, and washed essentially free of other bacteria, stored glycogen without lag when incubated with either compound.

The effect of other compounds on growth. When glucose was replaced by casein, bovine serum albumin, tryptone, yeast extract or single amino acids or fatty acids at $0.02 \%(\mathrm{w} / \mathrm{v})$, no growth occurred and glycogen storage was not stimulated. When yeast extract or tryptone were added to cultures excess bacterial growth occurred concurrently with a reduction in E.O. population, even if glucose $(0.02 \%, \mathrm{w} / \mathrm{v})$ was also present.

Re-inoculation into the rumen of a defaunated sheep freed of large bacteria. Both strains grew after their introduction into the rumen of an isolated canulated Clun Forest wether which had been defaunated of ciliate protozoa and from which the 'large bacteria' had been removed. The ciliate protozoa were removed by using dioctyl sodium sulphosuccinate (Abou 
Akkada et al. I968). This treatment was performed on two consecutive days. Two days later, $2 \mathrm{~g}$ of aureomycin was added via the cannula, and this resulted in the disappearance of the 'large bacteria' (selenomonads, Q.O., indigenous E.O. and Oscillospira guilliermondii) (Orpin, 197I). No E.O. appeared within six weeks of the defaunation, but a few O. guilliermondii and selenomonads were visible on microscopic examination of the rumen fluid. The aureomycin treatment was repeated, and two days later, $\mathrm{I} \cdot 68 \times 10^{8}$ E.O. strain I, grown in vitro, were suspended in $500 \mathrm{ml}$ of rumen fluid, freshly removed from the same sheep, and placed in the rumen. After 7 days, the population density of E.O. had increased from the estimated $2.8 \times \mathrm{IO}^{4} / \mathrm{ml}$ to $4 \times \mathrm{IO}^{4} / \mathrm{ml}$, and after 28 days was $9.4 \times 10^{6} / \mathrm{ml}$, after which the population remained constant. Four weeks later $O$. guilliermondii appeared, and after a further 14 days had reached a population density of $5 \times 10^{5} / \mathrm{ml}$, when the aureomycin treatment was repeated again before reinoculation. Strain 2 was also inoculated into the rumen of the same animal under the same conditions at a later date, reaching a maximum population density of $\mathrm{r} \cdot 4 \times 10^{8} / \mathrm{ml}$.

\section{DISCUSSION}

The cultural techniques necessary for the continued culture of E.O. were essentially similar to those used for certain rumen oligotrich protozoa (e.g. Coleman, I969). The failure of E.O. to grow in the absence of other bacteria or on a solid medium precluded the use of conventional bacteriological techniques. As with other rumen micro-organisms, the maintenance of anaerobic conditions was essential; the use of a reducing agent in the culture media combined with all operations being performed with $\mathrm{CO}_{2}$ flowing freely through all the containers was found to be satisfactory. The presence of a high population of other bacteria in the cultures probably also aided the maintenance of anaerobiosis. Under these conditions it was found unnecessary to remove the last traces of oxygen from the $\mathrm{CO}_{2}$ used; other workers have found this to be essential when growing single species of rumen bacteria in sterile media, even when reducing agents are employed.

The taxonomic position of E.O. has yet to be determined. Despite its large size, it seems likely that E.O. is a bacterium. It can be distinguished from the yeasts in being Gramnegative, motile and reproducing by binary fission to give daughters of equal size, and from the flagellate protozoa by the presence of a rigid wall and absence of both a discrete nucleus and locomotory organelles visible in the light microscope. This view is supported by electron microscopic examination (C. G. Orpin \& E. A. Munn, unpublished).

I wish to thank Dr P. Kemp for inserting the permanent rumen cannulae into the sheep used, Dr J. M. Eadie for the identification of the organism, and Miss H. P. I. Patmore for invaluable technical assistance.

\section{REFERENCES}

Abou Akmada, A. R., Bartley, E. E., Berube, R., Fina, L. R., Meyer, R. M., Hendricks, D. \& Julius, F. (1968). Simple method to remove completely ciliate protozoa from adult ruminants. Applied Microbiology 16, I475-I 477 .

Abou Akkada, A. R. \& El-Shazly, K. (1964). Effect of absence of ciliate protozoa from the rumen on microbial activity and growth of lambs. Applied Microbiology r2, 384-390.

Caldwell, D. R. \& Bryant, M. P. (1966). Medium without rumen fluid for nonselective enumeration and isolation of rumen bacteria. Applied Microbiology 14, 794-801.

Coleman, G. S. (1969). The cultivation of the rumen ciliate, Entodinium simplex. Journal of General Microbiology 57, $8 \mathrm{I}-90$.

EADIE, J. M. (I962). The development of rumen microbial populations in lambs and calves under various conditions of management. Journal of General Microbiology 29, 563-578. 
OrPIN, C. G. (I97I). The re-establishment of Eadie's Ovals, grown in vitro, in the rumen of a defaunated sheep. Journal of General Microbiology 68, xvii.

Orpin, C. G. \& Coleman, G. S. (1970). The cultivation of 'Ovals' from the ovine rumen. Journal of General Microbiology 63, xii.

PARK, J. T. \& JohNSON, M. J. (1949). A submicrodetermination of glucose. Journal of Biological Chemistry I8I, I 49-I II.

QUIN, J. I. (1943). Studies on the alimentary tract of Merino sheep in South Africa. VII. Fermentation in the forestomachs of sheep. Onderstpoort Journal of Veterinary Science and Animal Industry 18, 9I-I I 2.

WARNER, A. C. I. (1966). Diurnal changes in the concentration of micro-organisms in the rumen of sheep fed to appetite in pens or at pasture. Journal of General Microbiology 45, 243-25I. 